\title{
Classifications in Brief: Goutallier Classification of Fatty Infiltration of the Rotator Cuff Musculature
}

\author{
Jeremy S. Somerson MD, Jason E. Hsu MD, Jacob D. Gorbaty BA, \\ Albert O. Gee MD
}

Received: 21 August 2015/Accepted: 5 November 2015/Published online: 19 November 2015

(C) The Association of Bone and Joint Surgeons (B) 2015

\section{History}

Infiltration of the rotator cuff musculature with fatty tissue is a well-known feature of tears in the rotator cuff tendon. In a rabbit model, sectioning of the supraspinatus tendon resulted in increased adipose tissue in the muscle belly on histologic examination after 4 weeks [2]. The following year, Goutallier et al. [12] reported results of CT scans of the shoulder in patients undergoing repair of the rotator cuff. The injured shoulders showed greater fatty infiltration than normal, asymptomatic shoulders, which the authors classified in a spectrum of five stages [13].

With the advent of MRI to evaluate the rotator cuff, Fuchs et al. [7] compared CT and MRI assessment of fatty infiltration. Although interobserver agreement was good to excellent between musculoskeletal radiologists for CT and MRI evaluation individually, the correlation between CT and MRI grading of infiltration was only moderate. Fuchs et al. [7] attributed this to the improved ability of MRI to distinguish

Each author certifies that he or she, or a member of his or her immediate family, has no funding or commercial associations (eg, consultancies, stock ownership, equity interest, patent/licensing arrangements, etc) that might pose a conflict of interest in connection with the submitted article.

All ICMJE Conflict of Interest Forms for authors and Clinical Orthopaedics and Related Research ${ }^{\mathbb{B}}$ editors and board members are on file with the publication and can be viewed on request.

J. S. Somerson, J. E. Hsu, A. O. Gee ( $\square)$

Department of Orthopaedics and Sports Medicine, University of

Washington, Seattle, WA 98195, USA

e-mail:ag112@uw.edu

J. D. Gorbaty

University of Washington School of Medicine, Seattle, WA, USA between healthy muscle and fibrous tissue. Despite imperfect correlation with CT, the adaptation by Fuchs et al. for MRI is widely used $[8,10,11]$ owing to the shift to MRI as the predominant imaging study for rotator cuff injuries.

\section{Purpose}

The Goutallier classification serves primarily as a prognostic tool, which may help clinicians anticipate the potential benefits of various interventions. Fatty infiltration has been shown to be a poor prognostic factor for repair of the cuff tendons [4-6, 10, 14-17, 30]. Goutallier et al. [15] reported functional Constant and Murley score and radiographic (MRI and/or CT scans) outcomes for 220 shoulders undergoing rotator cuff repair; the rate of recurrent tear was greater in patients with fatty infiltration of the muscle. A longer-term study by Goutallier et al. [17] showed a strong correlation between the Constant and Murley score (a functional outcome score for the shoulder) at latest followup and preoperative fatty infiltration. In another study [10], preoperative fatty infiltration and muscle atrophy were found to be independent predictors for final American Shoulder and Elbow Surgeons and Constant and Murley scores after rotator cuff repair. Interestingly, fatty infiltration was a better predictor of outcome than either tear size or recurrence in that series. A meta-analysis investigating outcomes of rotator cuff repair showed a strong correlation between fatty infiltration and rate of retear, but available published data were too heterogeneous to determine whether clinical outcomes were affected [24].

Owing to its prognostic importance, surgeons have used the Goutallier classification to guide treatment options for rotator cuff tears [1]. The classification also has been used to define conditions for inclusion or exclusion in studies [3]. In addition, 
the simple numerical scale provides a means for clinicians to concisely communicate the severity of infiltration.

\section{Classification}

The original Goutallier classification had five stages, ranging from Stage 0 (normal muscle) to Stage 4 (more fat than muscle) (Table 1) [12, 13]. Fatty infiltration was characterized by areas of decreased radiodensity using noncontrast CT scans. Since the original description, the classification has been adapted for use with MRI (Fig. 1). The modification of Fuchs et al. [7] used the same grading system as Goutallier et al. [13], although a system using only three stages also was proposed (Table 1). Slabaugh et al. [31] proposed a simplified system as well, but combined Stages 2 and 3 rather than 3 and 4 based on their statistical analyses and proposed clinical significance of each stage.

Goutallier et al. [15] used axial CT cuts in a soft tissue window to grade each tendon. The supraspinatus was assessed at the section of the muscle with the greatest surface area between the scapular spine and the rest of the scapula. For the infraspinatus and subscapularis tendons, two sections were evaluated: a superior section at the level of the lateral attachment of the scapular spine and an inferior section at the lowest point of glenohumeral articulation.

For the MRI adaptation of the classification, there has been controversy regarding the ideal technique to use for grading. Fuchs et al. [7] used a T1-weighted turbo spin-echo sequence for grading; all muscles were evaluated at the most lateral parasagittal image on which the scapular spine was in contact with the scapular body. The superior and inferior parts of the subscapularis and infraspinatus muscles were evaluated separately and a mean was calculated like with the CT method. A similar method using MR arthrography was reported in another study using an oblique sagittal T1-weighted image selected at the level of the coracoid base [27]. More recently, Schiefer et al. [29] reported high intraobserver and interobserver agreement when investigators had full access to the examinations without specifying a definitive plane or image.

Table 1. Classification of fatty infiltration of the rotator cuff musculature

\begin{tabular}{llllll}
\hline Classification & Grade of FI & Grade of FI & Grade of FI & Grade of FI & Grade of FI \\
\hline $\begin{array}{l}\text { Goutallier et al. [13] } \\
\begin{array}{l}\text { Fuchs et al. } \\
\text { simplified grade }\end{array}\end{array}$ & Normal & 1 & 2 & Moderate & Severe \\
$\begin{array}{l}\text { [7] } \\
\text { Descriptive [13] }\end{array}$ & $\begin{array}{c}\text { Completely normal } \\
\text { muscle, without any } \\
\text { fatty streak }\end{array}$ & $\begin{array}{c}\text { Muscle contains } \\
\text { some fatty } \\
\text { streaks }\end{array}$ & $\begin{array}{c}\text { Fatty infiltration is } \\
\text { important, but there is } \\
\text { more muscle than fat }\end{array}$ & $\begin{array}{c}\text { Equal amounts of } \\
\text { fat and muscle }\end{array}$ & $\begin{array}{c}\text { More fat than } \\
\text { muscle is } \\
\text { present }\end{array}$ \\
\hline
\end{tabular}

$\mathrm{FI}=$ Fatty infiltration
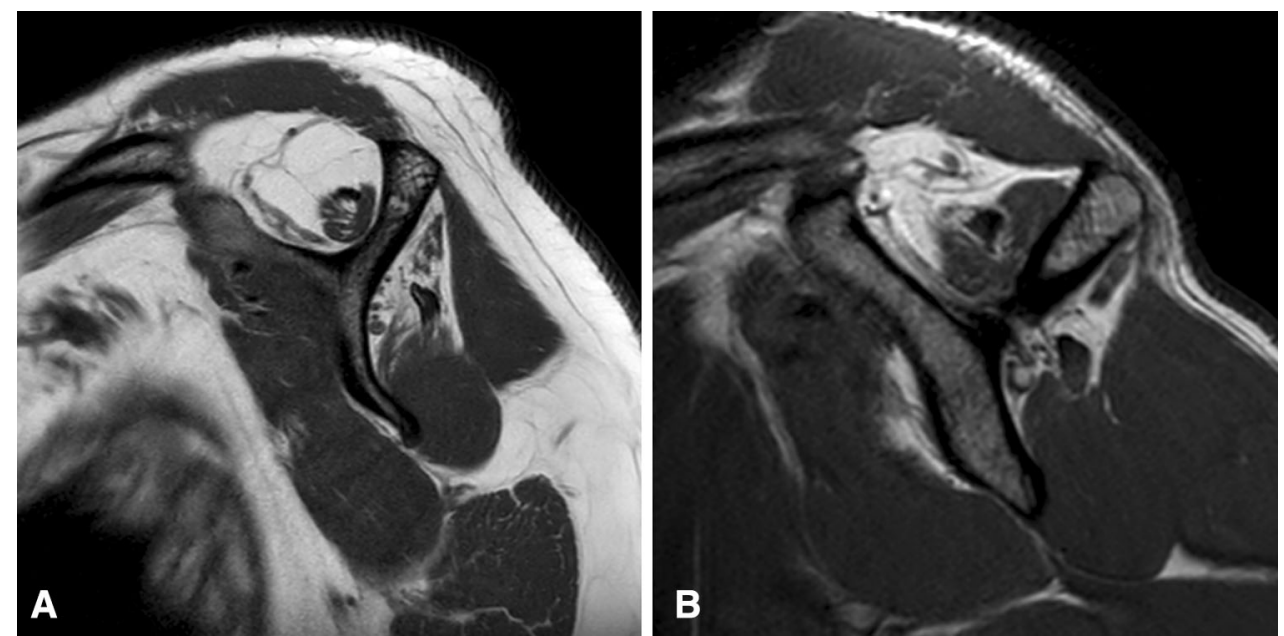

Fig. 1A-B T1 sagittal oblique images show (A) Grades 1, 4, 4, and 0 and (B) Grades $0,3,4$, and 0 fatty infiltration of the subscapularis, supraspinatus, infraspinatus, and teres minor, respectively. 


\section{Validation}

\section{Computed Tomography}

Fuchs et al. [7] reported interobserver agreement between two raters, a musculoskeletal radiologist and a radiology fellow. Weighted kappa values for agreement ranged from 0.68 to 0.83 , depending on the tendon selected; no intraobserver agreement was reported. Use of the proposed three-stage system did not result in meaningfully different results. Similar kappa values were reported in another study (intraobserver mean kappa, 0.69; interobserver mean kappa, 0.50) [34]. Lesage et al. [21] reported agreement among five independent raters using the original CT classification of Goutallier et al. for 56 shoulders. The interclass correlation coefficient was good for interobserver agreement (0.75), but a high level of intraobserver reliability was found only when limited to the three senior raters (0.78). This improved reliability highlights that the level of experience of the observer can affect the validity of a classification scheme.

\section{Magnetic Resonance Imaging}

Fuchs et al. [7] reported superior intraobserver agreement for MRI grading on a five-point scale compared with CT grading (Table 2). Another group [29] reported good interobserver and interobserver agreement among six raters using the MRI adaptation of the Goutallier et al. scale, including three shoulder surgeons and three musculoskeletal radiologists. The surgeons showed higher intraobserver agreement and interobserver agreement compared with radiologists. However, other studies have shown only moderate or poor intraobserver agreement (Table 2) [22, 27, 31, 32]. The reasons for the high variation among studies reporting reliability of this scale are unclear, but differences in methodology and specificity of which sequences and sections were used for grading may have played a role. Studies that only used a single representative image for grading tended to have lower interobserver reliability $[22,31]$, as did studies with 10 or more raters $[31,32]$.

\section{Limitations}

Despite attempts to standardize the grading system, there is lack of quantitative data in the classification of Goutallier et al. Recent efforts to more precisely quantify the amount of fatty infiltration have shown improved reliability with measurement of Hounsfield units on CT images [19] and

Table 2. Reported reliability of MRI grading of fatty infiltration

\begin{tabular}{|c|c|c|c|c|}
\hline Study & Year published & Scale used & Interobserver reliability (test) & Intraobserver reliability (test) \\
\hline \multirow[t]{2}{*}{ Fuchs et al. [7] } & 1999 & $\begin{array}{l}\text { Goutallier et al. } \\
\text { (5-point) }\end{array}$ & $0.82-0.93$ (weighted kappa) & \\
\hline & & $\begin{array}{l}\text { Fuchs et al. } \\
\text { (3-point) }\end{array}$ & 0.61-1.00 (weighted kappa) & \\
\hline Spencer et al. [32] & 2008 & $\begin{array}{l}\text { Goutallier et al. } \\
\text { (5-point) }\end{array}$ & 0.1 (kappa) & \\
\hline \multirow[t]{2}{*}{ Oh et al. [27] } & 2010 & $\begin{array}{l}\text { Goutallier et al. } \\
\text { (5-point) }\end{array}$ & $0.60-0.72$ (ICC) & $0.29-0.80$ (ICC) \\
\hline & & $\begin{array}{l}\text { Fuchs et al. } \\
\text { (3-point) }\end{array}$ & $0.60-0.75$ (ICC) & \\
\hline \multirow[t]{2}{*}{ Slabaugh et al. [31] } & 2012 & $\begin{array}{l}\text { Goutallier et al. } \\
\text { (5-point) }\end{array}$ & 0.43 (kappa) & 0.56 (kappa) \\
\hline & & $\begin{array}{l}\text { Slabaugh et al. } \\
\text { (3-point) }\end{array}$ & 0.61 (kappa) & 0.70 (kappa) \\
\hline Lippe et al. [22] & 2012 & $\begin{array}{l}\text { Goutallier et al. } \\
\text { (5-point) }\end{array}$ & 0.41 (kappa) & \\
\hline Wall et al. [33] & 2012 & $\begin{array}{l}\text { Goutallier et al. } \\
\text { (5-point) }\end{array}$ & 0.59-0.76 (weighted kappa) & $0.71-0.90$ (weighted kappa) \\
\hline Rulewicz et al. [28] & 2013 & $\begin{array}{l}\text { Goutallier et al. } \\
\text { (5-point) }\end{array}$ & 0.75 (weighted kappa) & \\
\hline Schiefer et al. [29] & 2015 & $\begin{array}{l}\text { Goutallier et al. } \\
\text { (5-point) }\end{array}$ & $0.61-0.82$ (weighted kappa) & 0.47-0.91 (weighted kappa) \\
\hline
\end{tabular}

ICC = interclass correlation coefficient. 
T2-sequence mapping [23] or two-point Dixon sequence measurements [26] for MRI scans. In addition, the relatively wide range of five stages has been cited as a potential reason for low reliability [32] and has resulted in simplified three-stage classifications. These simplified classifications have not met with widespread use and may cause confusion when communicating imaging findings. The radiation exposure of CT and cost considerations of MRI may limit the use of these modalities, particularly in a research setting. Ultrasound is a less-expensive modality that has comparable diagnostic performance to MRI for detecting fatty infiltration; however, results can be operator-dependent [33].

The physical cross-section of the examined muscle also may differ substantially depending on how far a torn tendon has retracted. Meyer et al. [25] showed, on MRI studies, that the superficial portion of the supraspinatus tendon reacts differently to tendon retraction than the deep portion, suggesting architectural changes in muscle belly fibers. These findings were confirmed in an experimental sheep model in which retracted tears had a greater amount of fatty infiltration [9]. A recent clinical study compared immediate postoperative MRI scans after rotator cuff repair with preoperative scans [18]. Interestingly, postoperative imaging showed an immediate improvement in Goutallier scores and tendon atrophy scores, suggesting that repositioning the tendon had a substantial effect on both.

Subjectivity of the grading system is an additional limitation, which some researchers have attempted to improve on by using quantitative analysis of cross-sectional imaging. One study used quantitative MRI measurements of the fat fraction in rotator cuff tendons and compared these with the Goutallier score [20]. Increasing fat fraction correlated well with a higher Goutallier score, aside from Grades 3 and 4, for which there was no difference. This method used manual outlining of rotator cuff muscle area on each MRI slice, which is time-consuming and may introduce some methodologic bias.

\section{Conclusions}

The classification of Goutallier et al. and its modifications have shown prognostic utility and often are used to guide treatment and define clinical study inclusion. A wide range of reliabilities for the classification has been reported, with most studies showing moderate or good agreement. Quantitative assessments, such as measurement of fat fraction volume, have the potential to improve the score's clinical precision and use.

\section{References}

1. Bergeson AG, Tashjian RZ, Greis PE, Crim J, Stoddard GJ, Burks RT. Effects of platelet-rich fibrin matrix on repair integrity of at-risk rotator cuff tears. Am J Sports Med. 2012;40:286-293.

2. Björkenheim JM. Structure and function of the rabbit's supraspinatus muscle after resection of its tendon. Acta Orthop Scand. 1989;60:461-463.

3. Burkhart SS, Barth JR, Richards DP, Zlatkin MB, Larsen M. Arthroscopic repair of massive rotator cuff tears with stage 3 and 4 fatty degeneration. Arthroscopy. 2007;23:347-354.

4. Choi S, Kim MK, Kim GM, Roh YH, Hwang IK, Kang H. Factors associated with clinical and structural outcomes after arthroscopic rotator cuff repair with a suture bridge technique in medium, large, and massive tears. J Shoulder Elbow Surg. 2014;23:1675-1681.

5. Deniz G, Kose O, Tugay A, Guler F, Turan A. Fatty degeneration and atrophy of the rotator cuff muscles after arthroscopic repair: does it improve, halt or deteriorate? Arch Orthop Trauma Surg. 2014;134:985-990.

6. Flury MP, John M, Goldhahn J, Schwyzer HK, Simmen BR. Rupture of the subscapularis tendon (isolated or in combination with supraspinatus tear): when is a repair indicated? J Shoulder Elbow Surg. 2006;15:659-664.

7. Fuchs B, Weishaupt D, Zanetti M, Hodler J, Gerber C. Fatty degeneration of the muscles of the rotator cuff: assessment by computed tomography versus magnetic resonance imaging. $J$ Shoulder Elbow Surg. 1999;8:599-605.

8. Gerber C, Fuchs B, Hodler J. The results of repair of massive tears of the rotator cuff. J Bone Joint Surg Am. 2000;82:505-515.

9. Gerber C, Meyer DC, Schneeberger AG, Hoppeler H, von Rechenberg B. Effect of tendon release and delayed repair on the structure of the muscles of the rotator cuff: an experimental study in sheep. J Bone Joint Surg Am. 2004;86:1973-1982.

10. Gladstone JN, Bishop JY, Lo IK, Flatow EL. Fatty infiltration and atrophy of the rotator cuff do not improve after rotator cuff repair and correlate with poor functional outcome. Am J Sports Med. 2007;35:719-728.

11. Gokalp G, Yildirim N, Yazici Z, Ercan I. Using chemical-shift MR imaging to quantify fatty degeneration within supraspinatus muscle due to supraspinatus tendon injuries. Skeletal Radiol. 2010;39:1211-1217.

12. Goutallier D, Bernageau J, Patte D. Assessment of the trophicity of the muscles of the ruptured rotator cuff by CT scan. In: Post M, Morrey B, Hawkins R, eds. Surgery of the Shoulder. St. Louis, MO: Mosby; 1990:11-13.

13. Goutallier D, Postel JM, Bernageau J, Lavau L, Voisin MC. Fatty muscle degeneration in cuff ruptures: pre- and postoperative evaluation by CT scan. Clin Orthop Relat Res. 1994;304:78-83.

14. Goutallier D, Postel JM, Chevalier X, Beaudreuil J, Zilber S. Intermediate term functional outcome prediction following full thickness rotator cuff tear reparative or not reparative surgery. Orthop Traumatol Surg Res. 2010;96:727-733.

15. Goutallier D, Postel JM, Gleyze P, Leguilloux P, Van Driessche $S$. Influence of cuff muscle fatty degeneration on anatomic and functional outcomes after simple suture of full-thickness tears. $J$ Shoulder Elbow Surg. 2003;12:550-554.

16. Goutallier D, Postel JM, Lavau L, Bernageau J. [Impact of fatty degeneration of the supraspinatus and infraspinatus muscles on the prognosis of surgical repair of the rotator cuff][in French]. Rev Chir Orthop Reparatrice Appar Mot. 1999;85:668-676. 
17. Goutallier D, Postel JM, Radier C, Bernageau J, Zilber S. Longterm functional and structural outcome in patients with intact repairs 1 year after open transosseous rotator cuff repair. $J$ Shoulder Elbow Surg. 2009;18:521-528.

18. Jo CH, Shin JS. Changes in appearance of fatty infiltration and muscle atrophy of rotator cuff muscles on magnetic resonance imaging after rotator cuff repair: establishing new time-zero traits. Arthroscopy. 2013;29:449-458.

19. Lee E, Choi JA, Oh JH, Ahn S, Hong SH, Chai JW, Kang HS. Fatty degeneration of the rotator cuff muscles on pre- and postoperative CT arthrography (CTA): is the Goutallier grading system reliable? Skeletal Radiol. 2013;42:1259-1267.

20. Lee S, Lucas RM, Lansdown DA, Nardo L, Lai A, Link TM, Krug R, Ma CB. Magnetic resonance rotator cuff fat fraction and its relationship with tendon tear severity and subject characteristics. J Shoulder Elbow Surg. 2015;24:1442-1451.

21. Lesage P, Maynou C, Elhage R, Boutry N, Herent S, Mestdagh H. [Reproducibility of CT scan evaluation of muscular fatty degeneration: intra- and interobserver analysis of 56 shoulders presenting with a ruptured rotator cuff muscles][in French]. Rev Chir Orthop Reparatrice Appar Mot. 2002;88:359-364.

22. Lippe J, Spang JT, Leger RR, Arciero RA, Mazzocca AD, Shea KP. Inter-rater agreement of the Goutallier, Patte, and Warner classification scores using preoperative magnetic resonance imaging in patients with rotator cuff tears. Arthroscopy. 2012;28:154-159.

23. Matsuki K, Watanabe A, Ochiai S, Kenmoku T, Ochiai N, Obata T, Toyone T, Wada Y, Okubo T. Quantitative evaluation of fatty degeneration of the supraspinatus and infraspinatus muscles using T2 mapping. J Shoulder Elbow Surg. 2014;23:636-641.

24. McElvany MD, McGoldrick E, Gee AO, Neradilek MB, Matsen FA 3rd. Rotator cuff repair: published evidence on factors associated with repair integrity and clinical outcome. Am J Sports Med. 2015;43:491-500.

25. Meyer DC, Pirkl C, Pfirrmann CW, Zanetti M, Gerber C. Asymmetric atrophy of the supraspinatus muscle following tendon tear. J Orthop Res. 2005;23:254-258.
26. Nozaki T, Tasaki A, Horiuchi S, Osakabe C, Ohde S, Saida Y, Yoshioka H. Quantification of fatty degeneration within the supraspinatus muscle by using a 2-point Dixon method on 3-T MRI. AJR Am J Roentgenol. 2015;205:116-122.

27. Oh JH, Kim SH, Choi JA, Kim Y, Oh CH. Reliability of the grading system for fatty degeneration of rotator cuff muscles. Clin Orthop Relat Res. 2010;468:1558-1564.

28. Rulewicz GJ, Beaty S, Hawkins RJ, Kissenberth MJ. Supraspinatus atrophy as a predictor of rotator cuff tear size: an MRI study utilizing the tangent sign. J Shoulder Elbow Surg. 2013;22:e6-e10.

29. Schiefer M, Mendonca R, Magnanini MM, Fontenelle C, Pires Carvalho AC, Almeida M, Chu AC, Silva SM, Visconti F, Ferreira GA, Franco JS. Intraobserver and interobserver agreement of Goutallier classification applied to magnetic resonance images. J Shoulder Elbow Surg. 2015;24:1314-1321.

30. Sethi PM, Noonan BC, Cunningham J, Shreck E, Miller S. Repair results of 2-tendon rotator cuff tears utilizing the transosseous equivalent technique. J Shoulder Elbow Surg. 2010;19:12101217.

31. Slabaugh MA, Friel NA, Karas V, Romeo AA, Verma NN, Cole BJ. Interobserver and intraobserver reliability of the Goutallier classification using magnetic resonance imaging: proposal of a simplified classification system to increase reliability. Am J Sports Med. 2012;40:1728-1734.

32. Spencer EE Jr, Dunn WR, Wright RW, Wolf BR, Spindler KP, McCarty E, Ma CB, Jones G, Safran M, Holloway GB, Kuhn JE; Shoulder Multicenter Orthopaedic Outcomes Network. Interobserver agreement in the classification of rotator cuff tears using magnetic resonance imaging. Am J Sports Med. 2008;36:99-103.

33. Wall LB, Teefey SA, Middleton WD, Dahiya N, Steger-May K, Kim HM, Wessell D, Yamaguchi K. Diagnostic performance and reliability of ultrasonography for fatty degeneration of the rotator cuff muscles. J Bone Joint Surg Am. 2012;94:e83.

34. Williams MD, Ladermann A, Melis B, Barthelemy R, Walch G. Fatty infiltration of the supraspinatus: a reliability study. $J$ Shoulder Elbow Surg. 2009; 18:581-587. 